\title{
Destination performance: Decision-making tools for tourism sector. The case of France
}

\author{
Aurélie Corne ${ }^{1}$
}

Received: 21/02/2017

\begin{abstract}
1 Institute of Business Administration, Department of Tourism Management, CRESEM (EA7397), University of Perpignan, 52 Avenue Paul Alduy, 66860 Perpignan, France; E-mail: aurelie.corne@univ-perp.fr
\end{abstract}

Supervisors: Eric Paget-Blanc and Bernardin Solonandrasana

Institution awarding the Ph. D. Degree: University of Perpignan, France

Date of defence: 09/12/2016

(c) 2017 Varna University of Management. All rights reserved

Citation: Corne, A. (2016) Destination performance: Decision-making tools for tourism sector. The case of France. Doctoral Dissertation Summary. European Journal of Tourism Research 17, pp. $265-268$

Goal and objectives of the dissertation

We postulate that tourist destination, which is the research subject of this study, is a complex system of interacting elements. Tourist Destination has to be marketed and managed. Thus, to maintain its position and attractiveness in a highly competitive environment, the Destination Management Organization (DMO) and professionals have to adopt operational strategies and tools for decision-making.

The purpose of this thesis is to analyse the performance, essentially through efficiency, of the tourist destination in order to identify the best practices (benchmarks) and provide managerial recommendations to decision makers. Through various actors and different scales of the French territory, we raise several issues related to performance optimization, a core research problem in management. The main purposes of this thesis lie in the use of decision-making with quantitative methods for tourism management.

\section{Methodology}

Data Envelopment Analysis (DEA) method is used throughout this dissertation. This method allows a performance analysis through the efficiency (characterized by the connection between the resources used and the results obtained). DEA method is a nonparametric approach based on linear programming. It was introduced and popularized by Charnes et al. (1978) and Banker et al. (1984). This method makes it possible to measure the relative efficiency of a given sample of decision-making units (DMU). This approach allows the identification of benchmarks that represent the best practices of the studied sector and gives managerial recommendations.

The second tool that has been used is the ELECTRE III method. This method is a part of the Multi-Criteria Decision Analysis (MCDA) 
approach. Initiated by Roy (1968), ELECTRE means "Elimination et choix traduisant la réalité" and aims to address various problems related to the management and especially in the real world of companies. Several types of methods exist but ELECTRE III is used because its permits to inform the decision by a classification of alternatives (through the identification of alternatives of criteria, weights and thresholds).

Finally, the third tool used is the fuzzy set Qualitative Comparative Analysis (fsQCA) method developed by Ragin (2008). fsQCA method works in the following way: conditions are determined which can explain a given result. Then it reveals paths formed by various combinations of conditions that are sufficient to explain the result, underlining the multiple and complex realities of tourism performance.

\section{Results}

Several applications concerning French territory and decision-makers are mobilised. The results are presented synthetically.

$\checkmark \quad$ The measure of the performance of midprice, economy and budget categories of the French hospitality sector has a potential to improve efficiency. Paris is therefore clearly the benchmark for the French hospitality sector. After Paris, the best conurbations are Dijon and Bordeaux.

$\checkmark$ The results show that budget hotels are more efficient than mid-price and economy categories.

$\checkmark$ There is a statistical difference in the efficiency score across the categories but no difference with the size of the conurbation.

$\checkmark$ Historical monuments have a significant impact on the destination performance.

$\checkmark$ The New Territorial Organization of the Republic (NOTRe reform) has no negative effects on the efficiency of France except for Lower-Normandy and Upper-Normandy regions.

$\checkmark \quad$ There is no relation between operational performance (producer side) and satisfaction (consumer side). This hypothesis is disconfirmed and shows that this relation is very complex. $\checkmark \quad$ The results of performance with booking satisfaction or with survey satisfaction are closer.

$\checkmark \quad$ The hypothesis is verified concerning the link between performance and environmental approaches.

$\checkmark$ This work provides results about the impacts of various contextual variables tested in the literature (localisation of DMO, category of DMO and legal nature) and four complex combinations appear to explain the performance of tourist offices of our sample:

- Two combinations reflect the case of a destination that would be more positioned on excursionists.

- Two combinations characterize the typical case of a tourist destination with attractions, accessibility and accommodation capacity.

\section{Theoretical conclusions}

This work highlighted the importance of destination management and reinforced the Ritchie and Crouch (2003) competitiveness model by integrating decision-making tools in order to make it more operational. This dissertation clarifies the conceptual framework linked to the tourist destination and contributes to the empirical literature on the notions of performance and benchmarking. It provides clarification on theoretical issues such as the relationship between customer performance and producer performance.

\section{Practical applications of the dissertation}

In order to assess the performance of French destination, several empirical studies have been carried out. To take different territorial scales of France and the multiplicity of actors in the tourism sector into account, applications are conducted on the French conurbations (the smallest territorial subdivision after the municipality) as well as on the French regions (which is the scale to analyse the new territorial organisation of the Republic - NOTRe Reform). Concerning the actors, these studies have concentrated on hotels because they concern around $2.5 \%$ in the French GDP in 2014) as well as on the DMO (institution very close to the territory). These studies permit to underline the margins of operation and the sources of performance for the destination, to question whether the 
producer performance is compatible with the customer performance or also the role of the digital and the labelling processes on the performance. To finish, our last study investigates the complexity of the tourist sector.

\section{Content of the dissertation}

First of all, the introduction of this dissertation shows the research context across the "French tourism paradox". In fact, since 1980, the French destination stands at the top in terms of tourist arrivals but unfortunately in the fourth position in terms of tourism expenditure. That's why, it's important to mobilize decision-making tools in order to understand and improve the competitiveness of the French destination. Then, this dissertation is divided into five chapters.

\section{Abstract of chapter one}

The purpose of the first chapter is to highlight the conceptual and methodological framework of this study specialised on destination management and performance. It aims to understand the tourism sector as a whole and sheds light on the concept of destination, competitiveness and tourist attraction from the manager's point of view. The first section of the chapter one focuses on the management of the destination and distinguishes the different decision-makers from the destination in order to identify the potential target of this research. Secondly, it offers a vision of performance in management sciences by presenting performance indicators and their measurement. It explains the tools necessary for the development of the destination, notably through the use of the efficient frontier method, which is present throughout this doctoral dissertation. The second section provides a literature review of the main work on benchmarking and performance analysis in the tourism sector using DEA method. Finally, it gives a critical overview at the existing literature in tourism management.

\section{Abstract of chapter two}

The second chapter is devoted to the management of the French tourist territory through two different scales: an approach carried out on the French conurbations and another on the French regions within the framework of the territorial reform NOTRe. The research design is presented in section one of the chapter. Different modes of governance are highlighted as well as the theoretical framework of the merger resulting from the new territorial division of France. Several assumptions are then tested in addition to the performance and benchmarking analyses. Indeed, the impact of various attractions, size of the conurbations as well as the categories of the hotels in connection with the performance are analysed. Then the NOTRe reform is also apprehended. In order to do this, the methodological framework is presented. It uses non-parametric methods based and derived from DEA (hierarchical model by Tone, 1997) and statistical tests. The section two deals with the empirical analysis. The data and the choice of the indicators are presented as well as the results obtained and the managerial implications arising from them.

\section{Abstract of chapter three}

After focusing on the French territories on various scales through the use of performance indicators related to the hotel sector, the third chapter analyses the players by taking an interest in the hotel entity. This chapter deals with the complex relationship between performance and satisfaction and offers a comparative analysis of hotel performance by examining, on the one hand, operational performance (producer side) measured by efficiency and, on the other hand, (consumer side) measured by the level of customer satisfaction. The first section of the chapter explains the notions of performance and satisfaction. The concept of satisfaction is detailed in order to underline the possible link between these two notions. The second section presents, first, multicriteria methods (Roy, 1968) and the algorithm of the ELECTRE III method, and then the data and the results obtained concerning the empirical comparison between operational performance and customer performance on a sample of hotels.

Abstract of chapter four

The fourth chapter focuses on labelling processes and e-WOM (electronic word-of- 
mouth). The goal of this chapter is to bring two new perspectives on the notion of output or result of tourist activity through two independent approaches: satisfaction (a subject that follows the third chapter) and environmental certifications. The first section of this chapter concerns the study on taking satisfaction into account in the analysis of performance as a result and deals with the definition of eWOM in the hotel industry. It also presents the empirical study, namely the research design, the methodology used (DEA bounded model, Tone, 1995), the results and the discussion. The second section analyses the performance of a sample of conurbations representative on the top of the range of hotel sector in France. This study confirms or invalidates the link between the adoption of environmental approaches and the performance of these establishments. The contribution of the signal theory (Spence, 1973) makes it possible to consider the certification labels as a signal of an environmental approach towards the consumer.

\section{Abstract of chapter five}

The fifth chapter is an exploratory study in order to take into account the multiple realities and the complexity of tourism sector. This chapter analyses the performance of a sample of Destination Management Organization and identifies the multiple paths leading to the tourism performance through the fuzzy set Qualitative Comparative Analysis (fsQCA) method. The first section of this chapter highlights the comparative qualitative analysis in management sciences and presents in detail the fsQCA method. The second section concerns its application to French DMOs. The role of tourist offices, the various legal forms and the touristic index are presented. The results of this chapter enrich the literature by the existence of multiple realities in terms of tourism performance.

\section{References:}

Banker, R.D., Charnes A. and Cooper, W.W. (1984). Some Model for Estimating Technical and Scale Inefficiency in Data Envelopment Analysis, Management Science, 30, 1078-1092.

Charnes, A., Cooper, W.W. and Rhodes, E. (1978). Measuring the efficiency of Decision- Making Units, European Journal of Operational research, 3, 429-444.

Ragin, C. (2008). Qualitative Comparative Analysis using fuzzy Sets (fsQCA). In B. Rihoux and C. Ragin (Eds.), Configurational Comparative Methods: Qualitative Comparatvie Analysis (QCA) and related techniques. Sage, Los Angeles.

Ritchie, J.R.B. and Crouch, G.I. (2003). The competitive Destination: a Sustainable Tourism Perspective, CAB International.

Roy, B. (1968). Classement et choix en présence de points de vue multiples (la méthode ELECTRE), Revue Informatique et Recherche Operationnelle, 8, 57-75.

Spence, A.M. (1973). Market signaling: information transfer in hiring and related processes. Cambridge, MA, Harvard University Press.

Tone, K. (1995). DEA models revisited. Communications of The Operational Research Society of Japan, 40, 681-685 (in Japanese).

Tone, K. (1997). DEA with controllable category levels. Proceedings of the Spring National Conference the Operation Research Society of Japan, 126-127. 